\title{
我国高性能合成橡胶材料发展现状与展望
}

\author{
徐林 $^{1}$, 曾本忠 ${ }^{2}$, 王超 ${ }^{1}$, 张付宝 ${ }^{2}$ \\ (1. 中国石化北京化工研究院燕山分院橡塑新型材料合成国家工程研究中心, 北京 102500; \\ 2. 中昊晨光化工研究院有限公司, 四川自贡 643201)
}

\begin{abstract}
摘要：合成橡胶材料广泛应用于工业、国防、交通及日常生活的各个方面，高性能和功能化通用合成橡胶是新时代发展所必 需的关键先进基础材料。本文结合产业数据调研结果，系统梳理了我国高性能合成橡胶材料的发展现状，总结了我国高性能 合成橡胶材料在生产、研发、应用等方面的主要问题。在此基础上提出了我国高性能合成橡胶材料的发展方向与建议，研究 认为应重点发展官能化溶聚丁苯橡胶、钕系顺丁橡胶、星型卤化丁基橡胶、功能化热塑性弹性体等高性能和功能化通用合成 橡胶, 以及氢化丁腈橡胶、热塑性硫化橡胶、高性能硅橡胶、氟醚橡胶等特种橡胶产品, 实现材料高端化、过程绿色化、生 产智能化。
\end{abstract}

关键词: 合成橡胶; 热塑性弹性体; 特种橡胶; 发展战略

中图分类号: TQ33 文献标识码: A

\section{Current Status and Prospects of High-Performance Synthetic Rubber in China}

\author{
Xu Lin ${ }^{1}$, Zeng Benzhong ${ }^{2}$, Wang Chao ${ }^{1}$, Zhang Fubao ${ }^{2}$ \\ (1. National Engineering Research Center for Synthesis of Novel Rubber and Plastic Materials, SINOPEC Beijing Research Institute of \\ Chemical Industry Yanshan Branch, Beijing 102500, China; 2. Zhonghao Chenguang Research Institute of chemical Industry Co. Ltd., \\ Zigong 643201, Sichuan, China)
}

\begin{abstract}
Synthetic rubber materials are widely used in industry, national defense, transportation, and daily life. High-performance and functional synthetic rubber is the key advanced base material necessary for the development of the new era. Based on industrial survey data, we systematically summarized the development status of high-performance synthetic rubber materials in China, analyzed the main problems in the production, research and development, application, and other aspects, and proposed the development direction and suggestions of the high-performance synthetic rubber materials in China. We suggest that China focus on the development of highperformance and functional synthetic rubber such as functionalized solution polymerized styrene-butadiene rubber, neodymium-based cis-1,4-polybutadiene rubber, branched butyl rubber, and functionalized thermoplastic elastomer, as well as special rubber materials such as hydrogenated nitrile rubber, thermoplastic vulcanized rubber, high-performance silicone rubber, and fluoroether rubber, thus to achieve high-end materials, green process, and intelligent production.
\end{abstract}

Keywords: synthetic rubber; thermoplastic elastomer; special rubber material; development strategy

收稿日期 : 2020-07-12; 修回日期 : 2020-08-30

通讯作者: 徐林, 中国石化北京化工研究院燕山分院橡塑新型材料合成国家工程研究中心高级工程师, 主要研究方向为合成橡胶;

E-mail: xulin.bjhy@sinopec.com

资助项目：中国工程院咨询项目“新材料强国 2035 战略研究” (2018-ZD-03)

本刊网址：www.engineering.org.cn/ch/journal/sscae 


\section{一、前言}

合成橡胶是三大合成材料之一，既是与人们生 产生活息息相关的石化产品, 也是重要的国家战略 资源，广泛应用于工业、国防、交通及日常生活的 各个方面。合成橡胶大致可分为通用橡胶和特种橡 胶两大类。通用合成橡胶指用于生产轮胎等大宗产 品的原料橡胶, 包括丁苯橡胶 (SBR)、聚丁二烯 橡胶（BR）、丁基/卤化丁基橡胶（IIR/HIIR）、乙 丙橡胶 (EPDM)、丁腈橡胶 (NBR)、异戊橡胶 (IR)、 氯丁橡胶 (CR) 和苯乙烯类嵌段共聚物 (SBCs) [1]; 高性能合成橡胶是指通用合成橡胶的高端牌号和功 能化品种以及特种合成橡胶, 是新时代发展所必需 的关键先进化工基础材料 [2]。

改革开放以来, 历经 40 余年高速发展, 我国 高性能合成橡胶材料产业从无到有, 从小到大, 得 到长足发展。相继成功开发出官能化溶聚丁苯橡胶、 钕系顺丁橡胶、星型卤化丁基橡胶、功能化热塑性 弹性体等高性能和功能化通用合成橡胶, 以及氢化 丁腈橡胶、热塑性硫化橡胶、高性能硅橡胶、氟梄 橡胶等特种橡胶产品。我国合成橡胶产业逐步迈向 高端化、绿色化、生产智能化的发展道路。

\section{二、高性能合成橡胶材料的特点及应用领域}

通用合成橡胶的高端牌号和功能化品种主要指 应用于高性能轮胎胎面、胎侧和气密层, 可以显著 提高轮胎性能的官能化溶聚丁苯橡胶、钕系顺丁橡 胶、星型卤化丁基橡胶; 以及用于苛刻条件下密封 防水、胶黏剂、聚合物改性、光缆电缆等领域的极 性化丁苯热塑性弹性体（SBS）、苯乙烯－异戌二烯 嵌段共聚物（SIS）、氢化苯乙烯－丁二烯嵌段共聚 物 (SEBS)、氢化苯乙烯异戊二烯共聚物 (SEPS) 热塑性弹性体、长链支化乙丙橡胶、官能化高抗 冲丁苯树脂等。特种合成橡胶材料是指不同于通 用橡胶材料而具有耐高低温、耐老化、抗烧蚀、 耐化学介质等特殊性能的橡胶材料, 主要包括氢 化丁腈橡胶 (HNBR)、热塑性硫化橡胶 (TPV)、 硅橡胶、氟橡胶等。特种合成橡胶材料具有的特 殊性能使其成为航空航天、国防军工、电子信息、 能源、环境、海洋等国家重大战略和新兴领域发
展所必需的关键材料 [3]。

当前和今后一段时期, 国防和国民经济发展 急需的先进通用橡胶和特种橡胶材料主要有以下 几种。

溶聚丁苯橡胶 (SSBR), 不同于传统乳聚丁苯 橡胶, 它是通过锂系阴离子溶液聚合制备的丁二烯、 苯乙烯共聚橡胶, 由于其结构可设计、性能可调控, 是制造轮胎胎面胶的理想胶种。作为高性能合成橡 胶胶种, 溶聚丁苯橡胶比乳聚丁苯橡胶有更优异的 滚动阻力和抗湿滑性能, 被公认为绿色轮胎的橡胶 复合体系中所必须采用的橡胶组分。

氢化丁腈棅胶是以改善丁腈橡胶（NBR）的耐 热和耐老化性能为目的, 将丁腈橡胶链锻上的丁二 烯单元进行选择性加氢制得的一种高饱和度橡胶材 料, 其最主要的特点是能在 $150^{\circ} \mathrm{C}$ 下长期使用, 并 且在高温下仍能保持较高的物理机械性能, 能够很 好地满足汽车、宇航、油田等领域对材料耐高温耐 化学品的特殊要求, 应用越来越广泛, 比如用作汽 车油封、燃油系统部件、汽车传动带、钻井保持箱 和泥浆用活塞、印刷和纺织用胶辊、航空航天用密 封件、减震材料等。

IIR/HIIR 是由异丁烯与少量异戊二烯通过低温 阳离子聚合反应合成的线型高分子材料。丁基橡胶 是气密性最好的橡胶, 在轮胎内胎、硫化胶囊、医 用胶塞和胶管胶带等领域有着广泛的应用。卤化丁 基橡胶包括澳化丁基橡胶和氯化丁基橡胶，是丁基 橡胶经过卤化改性的产品。卤化丁基橡胶在保持丁 基橡胶原有性能的基础上, 提高了产品硫化宽容度, 并且可与其他种类通用橡胶共硫化，可生产无内胎 轮胎, 且具有更好的耐热性。

氢化苯乙烯类热塑性弹性体（HSBCs）是热塑 性弹性体 SBS 和 SIS 经氢化后将绝大多数不饱和双 键变成饱和键, 不仅保留了本身优秀的弹性, 而且 耐热、耐光和耐热氧等性能得到大幅度提高。氢化 SBS（SEBS）可广泛用于生产高档弹性体、树脂 改性、胶黏剂、润滑油增黏剂、电线电缆的填充 料和护套料等。随着共享单车的兴起, SEBS 用于 生产不充气轮胎成为热门领域。氢化 SIS (SEPS) 主要用于润滑油增黏、透明弹性体和膜制品制造, 以及用在润滑油脂、光缆密封油膏、化妆品和涂 覆革等领域 [4]。 
异戊橡胶由异戊二烯合成，与天然橡胶结构最 为相近, 是天然橡胶的最佳替代品, 可用于轮胎等 行业。

热塑性硫化橡胶, 又称动态硫化热塑性弹性 体, 是通过在塑料相 (如聚丙烯) 和橡胶相 (如 EPDM）熔融共混过程中, 将橡胶相进行硫化, 得 到粒状硫化橡胶相以微区相态稳定存在于塑料相中 所制得的热塑性弹性体材料, 兼具传统橡胶的高弹 性能和塑料材料的热塑性加工性能, 具有密度低、 可回收、易加工、能耗低、长效耐老化性等优良的 特点。

硅橡胶是由线性聚硅氧烷混入补强填料以及功 能填料和助剂, 在加热、加压条件下硫化后成为网 状结构的弹性体的一类特殊合成橡胶。具有优异的 耐高低温、耐候、耐臭氧、抗电弧、电气绝缘性、 防潮、高透气性以及生理惰性等。在现代工业、电 子电气、汽车、建筑、医疗、个人护理等领域具有 广泛应用, 成为航空航天、国防军工、智能制造等 领域不可或缺的先进高性能材料。

氟橡胶是指主链或侧链的碳原子上含有氟原子 的一种含氟橡胶材料, 其特殊性能由氟原子的结构 特点所决定。氟橡胶可长时间在 $250^{\circ} \mathrm{C}$ 下使用, 极 限使用温度可达 $300^{\circ} \mathrm{C}$, 而传统三元乙丙橡胶、丁 基橡胶的极限使用温度只有 $150^{\circ} \mathrm{C}$ 。氟橡胶除了耐 高温还具有优异的耐油、耐化学介质、耐酸碱性能, 在所有橡胶弹性体材料中其综合性能最好, 主要用 于火箭、导弹、飞机、船舶、汽车等运载工具的耐 油密封和耐油管路等特种用途领域, 是国民经济和 国防军工不可或缺的关键材料。

\section{三、国内外高性能合成橡胶材料产业发展现状}

\section{（一）合成橡胶}

2017 年全球合成橡胶产能超过 $2 \times 10^{7} \mathrm{t} / \mathrm{a}$ 。 2018 年, 全球合计产能约为 $2.042 \times 10^{7} \mathrm{t} / \mathrm{a}$, 主要 分布于亚洲、北美及欧洲。中国是最大的生产国 和消费国, 年产能 $5.93 \times 10^{6} \mathrm{t}$, 约占全球总产能的 29\% [5,6]（见图 1)。

2020 年世界合成橡胶产能将达到 $2.2 \times 10^{7} \mathrm{t} / \mathrm{a}$ 。 各胶种中, 产能增幅最大的是 SSBR, 其次是 IIR 和 EPDM（见图 2）[6]。

2017 年全球生产合成橡胶（SR） $1.505 \times 10^{7} \mathrm{t}$, 同比增长 $1.4 \%$; 消费合成橡胶 $1.519 \times 10^{7} \mathrm{t}$, 同比 增长 $2.4 \%$ 。2018 年, 世界 SR 总产能为 $2.042 \times 10^{7} \mathrm{t}$, 产量为 $1.533 \times 10^{7} \mathrm{t}$, 产能利用率约为 $75 \%$, 产能总 体过剩。到 2025 年，产消量将分别接近 $2 \times 10^{7} \mathrm{t}$ 。

我国共有 50 家合成橡胶生产商, 产能合计为 $5.93 \times 10^{6} \mathrm{t} / \mathrm{a}$ 。已形成中国石化股份有限公司 $(29 \%)$ 、 中国石油股份有限公司（20\%）、民营企业（29\%）、 台资外资企业 (22\%) 的四分天下格局。中国石化 在 BR、SBCs 具有优势, 中国石油优势在 ESBR, 民营企业（共 32 家）的 IIR、IR 具有优势，台资 外资企业在 EPDM、NBR 上具有优势。

2017 年我国通用合成橡胶产量为 $3.557 \times 10^{6} \mathrm{t}$, 出口量为 $1.41 \times 10^{5} \mathrm{t}$, 进口量为 $1.365 \times 10^{6} \mathrm{t}$, 表观 消费量为 $4.781 \times 10^{6} \mathrm{t}$, 再创历史新高, 各主要胶种 供需情况详见表 1 。2 018 年产量为 $3.67 \times 10^{6} \mathrm{t}$, 产 能利用率为 $62 \%$ 。

2020 年, 我国合成橡胶需求将超过 $4.8 \times 10^{6} \mathrm{t} / \mathrm{a}$ 。

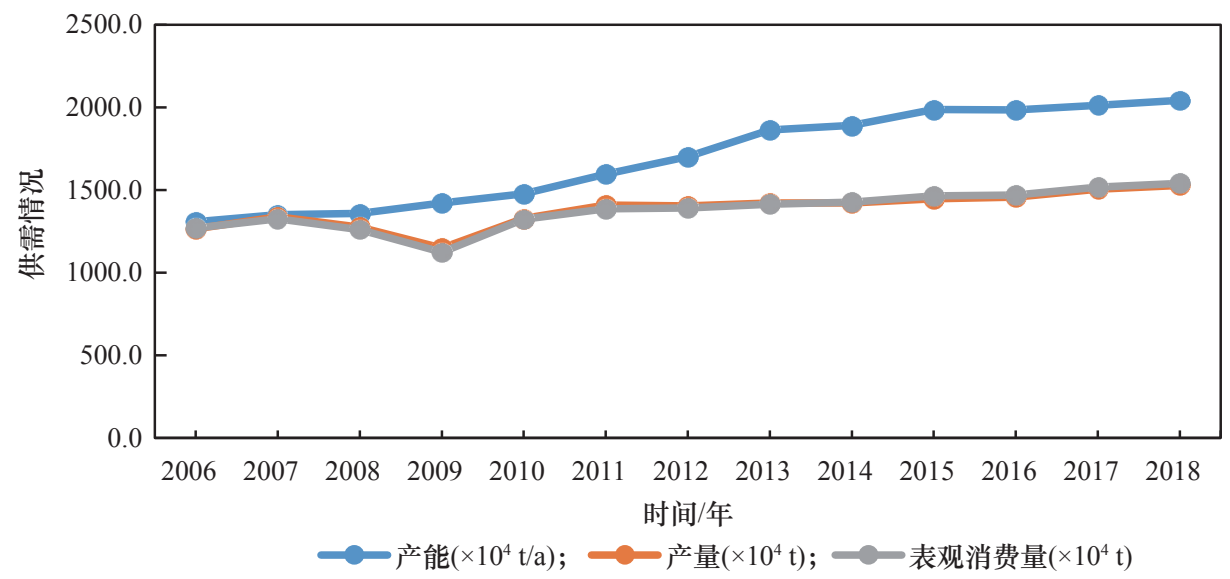

图 1 近年世界合成橡胶供需情况 $[5,6]$ 


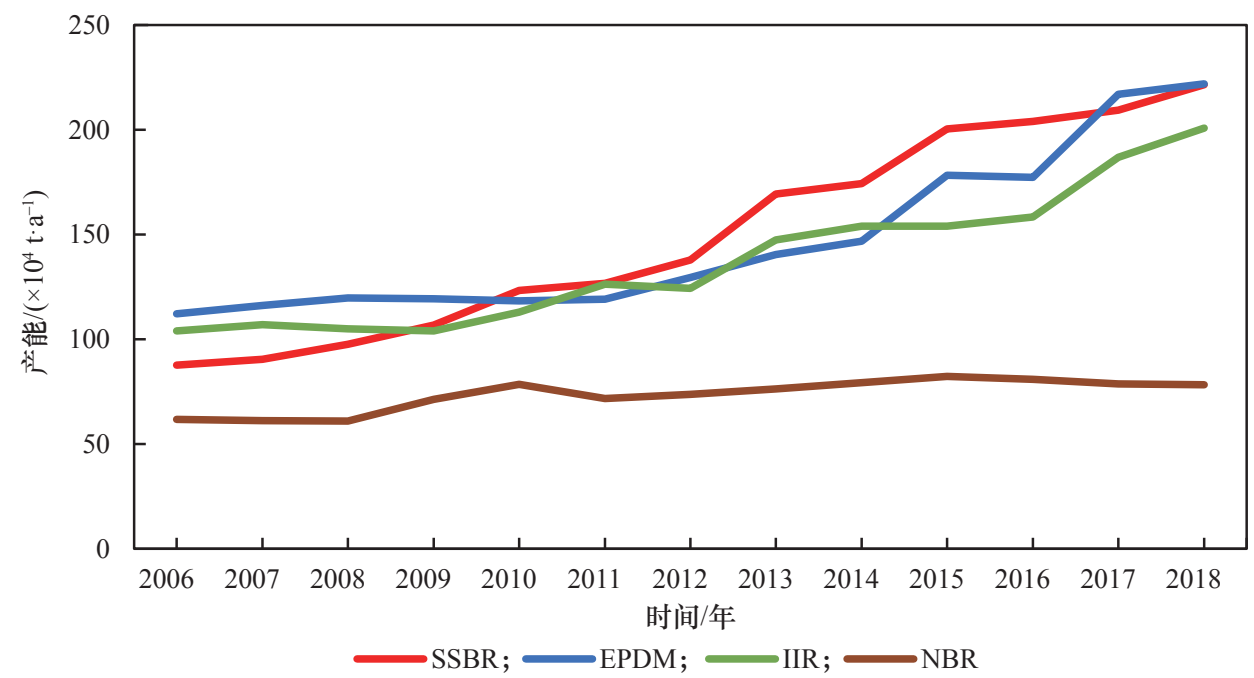

图 2 世界主要胶种近十年产能变化情况 $[5,6]$

表 12017 年中国大陆地区合成橡胶供需量 [7] $\times 10^{3} \mathrm{t}$

\begin{tabular}{lcccc}
\hline 合成橡胶 & 产量 & 出口量 & 进口量 & 表观消费量 \\
\hline ESBR & 1016 & 27 & 379 & 1368 \\
SSBR & 62 & 1 & 32 & 93 \\
BR & 965 & 42 & 268 & 1191 \\
EPDM & 183 & 13 & 212 & 381 \\
HIIR & 84 & 6 & 211 & 290 \\
NBR & 161 & 7 & 91 & 245 \\
IIR & 62 & 11 & 64 & 115 \\
IR & 71 & 2 & 44 & 113 \\
CR & 29 & 5 & 21 & 46 \\
SBCs & 924 & 27 & 43 & 940 \\
总计 & 3557 & 141 & 1365 & 4781 \\
\hline
\end{tabular}

国家经济结构转型在对合成橡胶业务提出产品结构 调整要求的同时, 也为先进基础材料业务的发展带 来难得的机遇。

\section{(二) 氟橡胶}

氟橡胶主要品种有常规二元氟胶、三元氟胶、 全氟醚橡胶、羧基亚硝基氟橡胶、氟化磷腈橡胶、 耐低温氟橡胶及氟硅橡胶等, 目前主要的氟橡胶厂 家和牌号如表 2 所示。

作为特种橡胶, 氟橡胶因氟原子赋予的特殊性 能，被用做各种苛刻条件下的密封材料。目前我国 常规的氟橡胶已实现产业化, 产业规模国际领先, 性能与国际相当, 特种氟橡胶也逐渐实现国产化,
产品的种类逐步完善。2017 年全球氟橡胶总产能约 为 $4.77 \times 10^{4} \mathrm{t} / \mathrm{a}$, 其中中国超过 $2.34 \times 10^{4} \mathrm{t} / \mathrm{a}$, 占全 球总产能的约 $50 \%$ 。近年来世界氟橡胶主要生产企 业如表 3 所示。

近年来氟橡胶的新建或拟建项目主要集中在 中国, 国外公司如大金工业株式会社已在常熟建 成 3200 t/a 装置 [8]; 索尔维特种聚合物 (常熟) 有 限公司也在常熟建成 $3000 \mathrm{t} / \mathrm{a}$ 装置, 杜邦旗下的科 慕公司与中昊晨光化工研究院有限公司合作拟建 $5500 \mathrm{t} / \mathrm{a}$ 装置。目前, 浙江巨化集团等公司也在规 划建设 $3000 \mathrm{t} / \mathrm{a}$ 的高性能氟橡胶装置。

2000 年以来, 随着国民经济的高速发展, 各国 对氟橡胶的需求量大幅度增长。2017 年全球需求量 约为 $3.35 \times 10^{4} \mathrm{t}, 2020$ 年将达 $4 \times 10^{4} \mathrm{t}$ 。2017年我国 的氟橡胶需求量约为 $1 \times 10^{4} \mathrm{t}$ 左右。预计 “十四五” 期间, 我国氟橡胶的需求量将达到 $1.5 \times 10^{4} \mathrm{t}$ 。随着 中国国防现代化建设的进一步加快, 新一代战车、 战斗机的研发促进了各种新型燃料、推动剂的应用, 氟橡胶在国防军事工业的应用领域已从密封件、电 气线路护套发展到各种新型燃料输油管道的主要成 型材料, 其市场潜力相当可观。目前国内氟橡胶生 产企业由于在产业规模、品种结构以及加工能力上 的差距, 尚无法完全满足军事工业需求。

\section{（三）硅橡胶}

有机硅属于高性能新材料, 全球有机硅需求复 合增速约为 $5 \%$ 。全球主要有机硅生产商包括美国 
表 2 氟橡胶主要生产厂家及牌号 [8]

\begin{tabular}{|c|c|c|c|c|}
\hline 共聚单体 & 生产厂家 & 典型商品牌号 & 国别 & 主要应用单位或领域 \\
\hline 偏氟乙烯 - 六氟丙 & $\begin{array}{c}\text { 杜邦公司 } \\
3 \mathrm{M} \text { 公司 } \\
\text { 大金工业株式会社 } \\
\text { 索尔维集团 }\end{array}$ & $\begin{array}{c}\text { VitonA 和 } \mathrm{E} \\
\text { Fluorel2140、2141 } \\
\text { Daiel G501、G801 } \\
\text { Techno flonsL、SH、NL } \\
\text { CK } \Phi-26 \\
\text { F26 系列 }\end{array}$ & $\begin{array}{l}\text { 美国 } \\
\text { 美国 } \\
\text { 日本 } \\
\text { 意大利 } \\
\text { 俄罗斯 } \\
\text { 中国 }\end{array}$ & $\begin{array}{l}\text { 上海道氟实业有限公司、上 } \\
\text { 海创奇特种橡胶制品有限公 } \\
\text { 司、成都道宏实业有限公司、 } \\
\text { 其他军工单位等 }\end{array}$ \\
\hline $\begin{array}{l}\text { 偏氟乙烯 - 六氟丙 } \\
\text { 烯 - 四氟乙烯 }\end{array}$ & $\begin{array}{c}\text { 杜邦公司 } \\
3 \mathrm{M} \text { 公司 } \\
\text { 大金工业株式会社 } \\
\text { 索尔维集团 }\end{array}$ & $\begin{array}{c}\text { VitonB } \\
\text { Fluorel2145、2230 } \\
\text { Daiel G601、G701 } \\
\text { Techno flonsT、TN、TH } \\
\text { F246 系列 }\end{array}$ & $\begin{array}{l}\text { 美国 } \\
\text { 美国 } \\
\text { 日本 } \\
\text { 意大利 } \\
\text { 中国 }\end{array}$ & $\begin{array}{l}\text { 上海道氟实业有限公司、上 } \\
\text { 海创奇特种橡胶制品有限公 } \\
\text { 司、成都道宏实业有限公司, } \\
\text { 安徽中鼎控股 (集团) 股份 } \\
\text { 有限公司、其他军工单位等 }\end{array}$ \\
\hline $\begin{array}{l}\text { 偏氟乙烯 - 六氟丙 } \\
\text { 烯 - 四氟乙烯 - 可 } \\
\text { 硫化单体 }\end{array}$ & $\begin{array}{c}\text { 杜邦公司 } \\
3 \mathrm{M} \text { 公司 } \\
\text { 大金工业株式会社 } \\
\text { 索尔维集团 }\end{array}$ & $\begin{array}{c}\text { VitonGH、GF } \\
\text { Fluorel2690、2460 } \\
\text { DaieG901、G902 } \\
\text { TechnoP459、P959 } \\
\text { FKM50XPL、FKM246-XP }\end{array}$ & $\begin{array}{l}\text { 美国 } \\
\text { 美国 } \\
\text { 日本 } \\
\text { 意大利 } \\
\text { 中国 }\end{array}$ & $\begin{array}{l}\text { 上海道氟实业有限公司、上 } \\
\text { 海创奇特种橡胶制品有限公 } \\
\text { 司、成都道宏实业有限公司, } \\
\text { 其他军工单位等 }\end{array}$ \\
\hline $\begin{array}{l}\text { 偏氟乙烯 - 三氟氯 } \\
\text { 乙烯 }\end{array}$ & $3 \mathrm{M}$ 公司 & $\begin{array}{l}\text { Kel-F5500、3700 } \\
\text { FKM2311、2301 }\end{array}$ & $\begin{array}{l}\text { 美国 } \\
\text { 中国 }\end{array}$ & 主要为国内军工单位 \\
\hline 四氟乙烯 - 丙烯 & 旭硝子株式会社 & Aflas100、150、TP-1 & 日本 & 特种需求应用领域 \\
\hline
\end{tabular}

表 3 氟橡胶主要生产厂家的生产能力和技术特点 [8]

\begin{tabular}{|c|c|c|c|}
\hline 企业名称 & 生产能力 $/\left(\mathrm{t} \cdot \mathrm{a}^{-1}\right)$ & 装置所在地 & 工艺技术 \\
\hline 杜邦公司 & 4500 & 美国（新泽西州 Decpwater） & $\begin{array}{l}\text { 技术先进, 工艺成熟, 产品种类齐全, 技术先进性 } \\
\text { 位居全球第一 }\end{array}$ \\
\hline $3 \mathrm{M}$ 公司 & 2500 & 美国（阿拉巴马州 Decatur） & 技术先进, 工艺成熟, 产品种类齐全 \\
\hline 索尔维集团 & 1500 & 美国（新泽西州 Thorofare） & 技术先进, 工艺成熟, 产品种类齐全 \\
\hline $3 \mathrm{M}$ 公司 & 2800 & 比利时（安特卫普） & 1986 年投产, 技术先进, 工艺成熟 \\
\hline 大金工业株式会社 & 1000 & 法国（Picrrc-Benite） & 2004 年投产, 技术先进, 工艺成熟 \\
\hline 索尔维集团 & 3500 & 意大利（Spinetta） & $\begin{array}{l}1986 \text { 年投产, 前身为 Ausimont 公司, 技术先进, 工 } \\
\text { 艺成熟, 产品种类齐全 }\end{array}$ \\
\hline 杜邦公司 & 3000 & 荷兰（Dordrecht） & 1986 年投产, 技术先进, 工艺成熟, 产品种类齐全 \\
\hline 旭硝子株式会社 & 1500 & 日本 (千叶县) & FEPM 型四丙氟橡胶, 技术先进, 位居全球第一 \\
\hline 大金工业株式会社 & 3000 & 日本（大阪） & 技术先进, 工艺成熟, 产品种类齐全 \\
\hline 小计 & 23300 & & \\
\hline
\end{tabular}

陶氏集团、美国迈图高新材料集团、日本信越集团 德国瓦克国际集团有限公司、中国蓝星（集团）股 份有限公司等, 生产装置主要分布在中国、美国、 德国、英国、日本、法国、韩国等国家 [9]。

2000 年以来, 随着我国成为世界制造业中心, 有机硅产业得到长足发展, 我国已经成为全球重要 的有机硅产销大国。截至 2017 年年底, 大陆地区 共有 13 家甲基硅氧烷单体生产企业, 聚硅氧烷总 产能为 $1.38 \times 10^{6} \mathrm{t} / \mathrm{a}$, 产量为 $1.02 \times 10^{6} \mathrm{t}$, 表观消 费量为 $9.7 \times 10^{5}$ t [10]; 2018 年，表观消费量首次超 过 $1 \times 10^{6} \mathrm{t}$, 达到创纪录的 $1.04 \times 10^{6} \mathrm{t}$, 同比增长
$7.4 \%$, 其中消费比例最大的是建筑、电子电气、医 疗及个人护理等领域。未来, 除了传统应用领域需 求仍将保持稳步增长以外, 新能源、人工智能、第 五代移动通信技术 (5G)、高端医疗等尖端应用领 域将助推我国硅橡胶行业走向高质量发展之路。

“十三五”期间我国硅橡胶行业在产业发展、 结构调整、技术进步、节能减排等方面取得了很 大进步，但在发展质量、技术水平、应用开发等 方面与世界先进水平相比依然存在较大差距。硅 橡胶生产规模小、集中度低、自动化程度低的格 局没有得到根本性改变, 安全环保、自动化生产 
技术有待进一步提高。

\section{四、我国高性能合成橡胶材料发展面临的主 要问题}

\section{（一）行业大而不强，企业竞争力弱}

进入 21 世纪以来, 随着国民经济的高速发展, 国内合成橡胶产业快速增长, “十一五” “十二五” 的十年间，国有、民营及台 / 外资企业都热衷于投 资合成橡胶产业, 导致国内产能出现井喷式增长, 增幅明显高于国内同期合成橡胶产量与消费量的增 幅。然而从 2008 年开始出现了过剩迹象，2012 年 之后过剩态势逐步扩大。受市场价格和生产成本的 影响, 加之进口产品的冲击。2017 年国内合成橡胶 产量共计 $3.557 \times 10^{6} \mathrm{t}$, 有效产能利用率为 $64.0 \%$, 低于世界合成橡胶装置平均产能利用率 8.8 个百分 点。调整产品结构、提高市场竞争力, 已成为合成 橡胶工业面临的首要问题 [7]。

\section{（二）中高端牌号供给不足, 短缺与结构性过剩 并存}

历经 70 年发展, 我国已经能够生产所有的通 用合成橡胶品种, 产能、产量、消费量也跃居世界 首位。但也存在产品同质化严重等问题, 高附加值 产品占比依然较低, 很多特种高性能产品长期依赖 进口。仅有异戍橡胶工业装置突破了传统技术范式, 采用稀土催化体系, 通过全新的技术路线, 实现了 异戍橡胶的产业化，但也存在产品质量不稳定等问 题。高端的溶聚丁苯橡胶、溴化丁基橡胶主要以进 口为主, 中国目前还不能生产高门尼黏度乙丙橡胶 的牌号。丁腈橡胶仅有 20 多个牌号, 其中超高腈丁 腈橡胶 (NBR)、羧基丁腈、氢化丁腈、粉末丁腈等 牌号产品还主要依靠进口。国内氟橡胶在品种、应 用方面尚存在较大差距, 特别是加工应用技术的落 后, 如汽车曲轴油封、燃油管等氟橡胶密封件目前 均被国外巨头所控制。此外, 民航、石油、化学和 医疗、建筑、发光二极管 (LED)、太阳能电池等 其他高端领域的氟橡胶制件水平也处于落后地位。

\section{（三）创新能力不强, 新技术开发差距明显}

面向未来，国际合成橡胶领域不断加强技术创 新, 新技术开发主要集中在产品创新、工艺创新和
环境友好三个方面。

在产品创新方面, 主要依托可控自由基聚合、 可控正离子聚合等基础研究成果, 开发具有全新结 构和性能的合成橡胶新产品。我国合成橡胶企业在 此领域的研究刚刚起步。

在工艺创新方面, 主要围绕生产工艺的优化、 设备的改进、产品应用配方的开发等方面开展创新 研究, 以提升装置的综合技术水平。我国合成橡胶 企业在此方面的原创性不多。

在环境友好方面, 一是围绕生产绿色轮胎的高 性能合成橡胶新牌号进行创新开发, 以期全面改善 轮胎的抗湿滑性, 滚动阻力和燃油经济性; 二是围 绕环保要求, 开发符合环保法规要求的新型助剂和 填充油; 三是围绕原料绿色化, 开发以生物质为原 料的合成橡胶。目前在绿色轮胎用高性能溶聚丁苯、 稀土异戊等新牌号开发方面, 还缺乏面向市场的专 业化技术服务支持。

\section{（四）中美贸易摩擦对合成橡胶领域的影响}

在橡胶领域, 中美贸易摩擦已历经多年, 2009年 以来, 美国相继对我国输美乘用车与轻型卡车轮胎 实施多轮附加关税。轮胎特保案对中国轮胎出口, 特别是低端轮胎领域带来了很大的冲击。我国合成 橡胶出口到美国相对较少，但是以橡胶制品方式大 量的出口, 中美贸易摩擦对我国橡胶制品的出口 造成较大的影响, 从而导致合成橡胶产品需求下 降, 企业开工率下降。另一方面高端或专用橡胶 品种牌号虽然大部分不是由美国进口, 但是供应 国有可能在美国的压力下限制对华出口，从而影 响到相关领域。

我国合成橡胶行业实现了所有通用产品技术的 自主化, 为保障国家经济发展提供了有力的战略支 撑。但是不少特殊用途牌号依然要依赖进口, 因此 我们应该重点发展合成橡胶高端产品, 通过 “产学 研用”一体化开发, 补齐短板。

\section{五、我国高性能合成橡胶材料的战略目标 与发展任务}

\section{(一) 战略目标}

1. 材料高端化

重点发展官能化溶聚丁苯橡胶、钕系顺丁橡胶、 
星型卤化丁基橡胶。其应用领域为高性能轮胎胎面、 胎侧和气密层, 占合成橡胶总消耗量的 $60 \%$ 。

发展极性化 SBS、SIS, 氢化 SEBS、SEPS 热 塑性弹性体、长链支化乙丙橡胶、官能化高抗冲丁 苯树脂等, 主要应用于密封防水、胶黏剂、电线电 缆等, 占合成橡胶总消耗量的 $21 \%$ 。

发展特种氢化丁腈橡胶、热塑性硫化橡胶、高 性能硅橡胶、氟醚橡胶等产品。其主要应用于海洋 橡胶制品、止水带、轨道交通（减震、密封）橡胶 制品以及航空航天、特种作业等领域。力争到 2025 年, 建立较为完善的高性能硅橡胶功能填料评价体 系和产品应用评价体系; 实现氟醚用特种单体产业 化, 制备出接近国际先进水平的全氟梄橡胶和不需 二段硫化的氟橡胶。

\section{2. 过程绿色化}

过程绿色化发展主要的努力方向是改进现有生 产工艺, 实现节能降耗, 包括新型反应器开发、合 成橡胶干燥工艺节能技术、合成橡胶生产质量控制 技术等; 开发绿色生产和环保技术, 包括低排放生 产工艺、挥发性有机化合物（VOC）处理和污水减 排技术、低能耗生产技术, 乳液聚合提浓技术、环 保型助剂替代技术; 探索基于生物材料合成双烯烃 技术。

\section{3. 生产智能化}

基于人工智能网络技术, 整合数据资源, 实现 弹性体材料分子设计、合成工艺和加工应用研究的 高速有效性。

我国工业进入 4.0 时代, 将数字化、智能化、 模块化、网络化等新型理论与工具引入到合成橡胶 材料技术开发中, 形成一套完整的自有数据库, 通 过电脑模型模拟出产品结构、性能与可能应用的领 域, 使产品的基础研究、生产技术开发、产品应用 研究具有一套完整的模拟评价体系, 客户可以根据 需求随时定制高端产品, 能快速设计、开发、生产, 进入市场, 在技术开发与产品应用开发中引领国际 市场，高端化产品达到 70\% 以上。

整合先进的制造技术、装备技术、自控技术、 环保技术, 实现合成橡胶生产过程智能化、绿色低 碳。使产品的基础研究、生产技术开发、产品应用 研究形成高效的链条, 实现客户-研发-生产 - 销 售智能化高效定制系统。

\section{（二）重点发展任务}

\section{1. 官能化溶聚丁苯橡胶}

加快开发具有低油耗、高安全、低噪音和舒适 性的高性能节能胎面胶。着重开发高端牌号 SSBR, 形成具有自主知识产权的官能化 SSBR 生产技术, 构建我国高性能 SSBR 新产品、新方法的知识产权 保护网络, 在技术上达到国际先进水平。

\section{2. 氢化丁腈橡胶}

国外 HNBR 产品主要集中在腈含量在 $22 \%$ $45 \%$ 的 HNBR 常规牌号上。我国正处在完成 HNBR 工业化的进程当中, 目标牌号也主要是常规 HNBR 产品。由于国外公司禁售某些特种牌号产品。因此, 开发特种牌号 HNBR 橡胶将成为发展重点, 包括宽 温域 HNBR、耐低温耐油的 HNBR 以及开发新型特 种 HNBR 产品等。

3. 丁基 / 卤化丁基橡胶

加大基础研究, 优化分子结构设计, 开发出特 异性能的支化丁基橡胶、新型卤化丁基橡胶产品。 同时集中力量突破关键核心设备的设计与制造技 术。实现国内现有装置与生产技术的提升, 形成 稳定的规模化生产, 加强产品加工应用技术开发 与市场推广力度, 到 2035 年实现从基础研究、工 业技术、加工技术到高性能产品在尖端领域示范 应用的全方位技术突破, 生产技术和产品达到世 界一流水平 [11]。

\section{4. 苯乙烯类热塑性弹性体及其氢化产品}

通过向苯乙烯类热塑性弹性体中引入高玻璃化 转变温度的单体, 在聚合物主链上引入极性丙烯酸 酯支链等手段, 设计并合成具有新颖结构的聚合物, 提高材料的耐温、耐磨和弹性, 改善现有不充气轮 胎的舒适感、耐磨性和耐温性能。

实现磺化改性 SBS、环氧化 SBS、高极性 SBS 等功能化苯乙烯类热塑性弹性体的商品化, 并成功 应用于油田、医疗等特殊领域。加大合成新方法研 究, 特别是基于可逆加成 - 断裂链转移 (RAFT) 聚合在合成非苯乙烯类热塑性弹性体 (SBC) 类新 型嵌段结构热塑性弹性体方面的最新进展。建立新 型热塑性弹性体技术开发平台和性能评价体系, 为 新型功能性热塑性弹性体的大规模应用奠定基础。

5. 异戍橡胶

我国的顺式异戊橡胶装置都采用稀土催化剂, 
产品性能优于传统 $\mathrm{Ti}$ 系催化异戊橡胶。但新技术 在生产工艺技术方面还处在成长期, 在催化剂体系、 制备方法、反应设备、聚合工艺等方面仍有较大的 提升空间。

\section{6. 热塑性硫化橡胶}

为了适应橡塑共混型热塑性弹性体材料的快 速发展, 一方面要强化 EPDM/PP、IIR/PP 等传统 $\mathrm{TPV}$ 材料的技术开发与应用研究, 另一方面, 随着 动态硫化技术和相关机理的不断发展成熟, 基于不 同组分的、可满足不同性能要求的高性能特种 TPV 材料不断涌现，未来应重点开发高气体阻隔性异丁 烯 - 对甲基苯乙烯共聚橡胶 / 尼龙 TPV、耐高温耐 化学介质的丙烯酸酯橡胶基 TPV 和氟橡胶基 TPV、 具有高体感相容性的硅橡胶基 TPV 以及绿色环保 可降解的生物基 TPV 等。

\section{7. 特种硅橡胶}

苯 (醚) 撑硅橡胶、含特种元素（如嗍、氮等） 的硅橡胶等耐高温硅橡胶品种的开发关键在于特种 耐高温有机硅单体的规模化制备。这些单体包括含 耐高温基元的二硅醇, 如亚苯基二硅醇、二苯醚二 硅醇、碳硼烷二硅醇等, 也包括专用活性聚合单体, 如双艮基硅烷等。应力争在耐高温有机硅单体的制 备、特种催化剂制备、聚合反应控制等方面尽快取 得突破。

\section{8. 特种氟橡胶}

汽车工业是氟橡胶的主要消费领域, 用量约占 氟橡胶总消费量的 $40 \%$, 石油化工占 $25 \%$, 航天、 航空及其他行业占 $35 \%$ 。随着各行业在节能、环保 等方面越来越高的要求，传统橡胶材料已不能满足 新的使用要求, 为氟橡胶代替其他橡胶制品提供了 机遇。相对国外氟橡胶, 我国的氟橡胶主要在特种 聚合单体方面存在不足、生产装置的自动化和智能 化较为落后, 特种聚合单体的合成技术和提升装置 的自动化、智能化是下一步氟橡胶产品实现突破的 关键。

\section{六、措施建议}

\section{（一）制定规划，重点支持，加强产业链协同创新}

根据世界合成橡胶技术发展的大趋势，在国家 层面设立创新专项, 给予重点支持, 以企业为主体,
“产学研用”协同创新。积极开展高性能合成橡胶 材料研究，从合成机理、工艺路线优化、装备与数 字自动化、新的应用领域开发等方面共同开发。形 成完整的上下游创新链, 推动行业跨越式发展, 以 满足我国高性能合成橡胶新材料快速发展的需求。

\section{（二）加强宏观调控，优化产业结构}

在宏观产业政策、信贷政策以及行业组织层面 加强宏观调控作用，制定相关政策，鼓励企业开展 高技术含量合成橡胶材料的研发和工业化，限制低 端技术来源的新建或扩建项目，增强对核心技术的 研发和掌控能力, 实现产业结构的优化。

\section{（三）建设国家级创新平台，打造一流创新团队}

加强科研人才培养，集中优势科研力量，优化 科研成果转化奖励机制, 提升内动力, 打造具有国 际一流开发创新能力和自我发展能力的高性能橡胶 材料创新团队，推动行业健康发展。

\section{参考文献}

[1] 焦书科, 周彦豪. 橡胶弹性物理及合成化学 [M]. 北京: 中国石 化出版社有限公司, 2008 .

Jiao S K, Zhou Y H. Rubber elastic physics and synthetic chemistry $[\mathrm{M}]$. Beijing: China Petrochemical Press Co., Ltd., 2008.

[2] 化工、治金、材料领域课题组. 化工、治金与材料领域颠覆性技 术影响初探 [J]. 中国工程科学, 2018, 20(6): 34-41.

The Research Group of Chemical, Metallurgical, and Material Fields. Preliminary study on impact of disruptive technologies in chemical, metallurgical, and material fields [J]. Strategic Study of CAE, 2018, 20(6): 34-41.

[3] 曹湘洪, 袁晴棠, 刘佩成. 中国石化工程科技2035发展战略研究 [J]. 中国工程科学, 2017, 19(1): 57-63.

Cao X H, Yuan Q T, Liu P C. Development strategy for China's petrochemical engineering science and technology to $2035[\mathrm{~J}]$. Strategic Study of CAE, 2017, 19(1): 57-63.

[4] 钱伯章. 国内首套氢化苯乙烯-异戊二烯共聚物工业化装置建 成投产 [J]. 橡胶科技, 2017, 15(10): 33.

Qian B Z. Startup of Chinese first SEPS plant [J]. Rubber Science and Technology, 2017, 15(10): 33.

[5] 杨秀霞, 王殿铭, 吕晓东. 国内外合成橡胶市场现状及发展前景 探析 [J]. 当代石油石化, 2019, 27 (6): 13-20.

Yang X X, Wang D M, Lyu X D. The analysis and prospect of domestic and foreign synthetic rubber market $[\mathrm{J}]$. Petroleum \& Petrochemical Today, 2019, 27 (6): 13-20.

[6] IISRP. Worldwide rubber statistical [R]. Houston: International Institute of Synthetic Rubber Producers, Inc, 2017-2019.

[7] 中国合成橡胶工业协会秘书处. 2017 年国内合成橡胶产业回顾 及展望 [J]. 合成橡胶工业, $2018,41(2)$ : 81-83. 
China Synthetic Rubber Industry Association Secretariat. Retrospection and prospect of domestic synthetic rubber industry in 2017 [J]. China Synthetic Rubber Industry, 2018, 41(2): 81-83.

[8] 邬一凡, 黄巍, 徐京生. 国内外氟橡胶生产消费现状及发展趋势 [J]. 化工新型材料, 2013 (3): 1-5.

Wu Y F, Huang W, Xu J S. Current situation and development trends of production \& consumption on fluoroelastomers at home and abroad [J]. New Chemical Materials, 2013 (3): 1-5.

[9] 金晖. 三氯氢硅氯循环利用产业链的构建 [J]. 广东化工, 2020 47(12): $120-121$.

Jin H. Construction of industrial chain based on chlorine recycling of trichlorosilane [J]. Guangdong Chemical Industry, 2020, 47(12): 120-121.

[10] 赵立群. 我国有机硅产业链发展态势分析 [J]. 化学工业, 2019, 37(1): 10-20.

Zhao L Q. Analysis on the development trend of China sillicone industry chain [J]. Chemical Industry, 2019, 37(1): 10-20.

[11] 曹湘洪. 创新驱动 结构调整 做强中国合成橡胶工业(下) [J]. 中 国橡胶, 2014, 30(21): 18-21.

Cao X H. Innovation drives structural adjustment to strengthen China's synthetic rubber industry (II) [J]. China Rubber, 2014, 30(21): 18-21. 